TRANS · núm. 25.202I

MISCELÁNEA $\cdot 199-222$

LITERARIA
El objetivo del presente artículo es analizar comparativamente el uso de diminutivos en español y en alemán desde una perspectiva semántica y pragmática. El corpus lingüístico específico que se somete a examen es la novela Últimas tardes con Teresa de Juan Marsé, en su versión en español en contraste con su traducción al alemán por Andrea Rössler (1991). La razón que ha motivado la selección de este corpus textual es que ofrece un amplio elenco de ejemplos de diversa índole que nos permiten aproximarnos a la variada casuística del empleo de los diminutivos en español, a la vez que ponen de manifiesto la dificultad de reproducir determinados rasgos semánticos y pragmáticos del texto original al verterlo al alemán. En última instancia, el uso de los diminutivos ilustra paradigmáticamente las peculiaridades estilísticas de un texto que, por sus propias características argumentales y lingüísticas, se plantea como polifónico, lo que supone todo un desafío para su traducción.

PALABRAS CLAVE: traducción de sufijos diminutivos, semántica, pragmática, español, alemán, traducción literaria.

\title{
Análisis comparativo de la función semántico-pragmática del uso de los diminutivos en la traducción literaria español-alemán: el caso de Últimas tardes con Teresa de Juan Marsé*
}

\author{
José Manuel Blanco Mayor \\ Universität Rostock
}

\section{A Comparative Analysis of the Semantic and Pragmatic Function of Diminutives in Literary Translation from Spanish into German: the case of Últimas tardes con Teresa by Juan Marsé}

This paper aims to offer a comparative analysis of the use of diminutives in Spanish and German from the point of view of semantics and pragmatics. Specifically, the linguistic corpus which is examined is the novel últimas tardes con Teresa by Juan Marsé. The Spanish version is contrasted with the German translation by Andrea Rössler (1991). The vast range of examples that instantiate the variety of uses of diminutives in Spanish justifies the choice of this textual corpus. Not least, it shows how difficult it is to reproduce some semantic and pragmatic traits of the original Spanish text in the translation into German. Ultimately, the use of diminutives illustrates paradigmatically the stylistic features of a text that, considering its plot and linguistic characteristics, turns out to be polyphonic - a true challenge for any translation.

KEY WORDS: translation of diminutive suffixes, semantics, pragmatics, Spanish, German, literary translation.

\footnotetext{
* Quisiera expresar mi agradecimiento a Beate Kern, quien leyó un esbozo de este trabajo y me animó a publicarlo. Asimismo, agradezco a los revisores anónimos sus valiosas sugerencias.
} 
Últimas Tardes con Teresa dramatiza el encuentro entre dos clases sociales bien diferenciadas: Manolo, apodado el Pijoaparte, muchacho de extracción humilde y escasa formación educativa, seduce y se enamora de Teresa, una joven burguesa universitaria. Sobre todo las partes dialogadas reproducen variedades diastráticas del castellano e incluso, en ocasiones, incorporan variedades diatópicas propias del español hablado en Cataluña. Al margen de ello, la presencia de determinados conceptos de realia propios de la España —y, específicamente, de la realidad barcelonesa de mediados del siglo $\mathrm{xx}$ puede generar dificultades hermenéuticas para un lector moderno, y, por ende, contribuye a crear una barrera interpretativa adicional desde el punto de vista traslaticio. A estas dificultades se enfrenta la traducción al alemán realizada por Andrea Rössler (1991).

Nuestro objetivo en relación con la novela es doble: por una parte, estudiaremos los usos semánticos y pragmáticos de los diminutivos de manera intrínseca, esto es, desde la perspectiva interna del funcionamiento de la lengua española. Por otra parte, también se abordará el corpus textual desde una perspectiva translingüística y transcultural: a través del análisis comparativo con la versión en alemán trataremos de comprobar en qué medida y por medio de qué recursos los valores semánticos y pragmáticos inherentes a los sufijos diminutivos en el texto fuente permanecen inalterados o bien sufren modificaciones al verse trasvasados a una lengua que se rige por unas normas morfológicas, semánticas y pragmáticas no coincidentes (o, al menos, no siempre coincidentes) con el español.

\section{CUESTIONES TEÓRICO-METODOLÓGICAS}

\subsection{Los diminutivos: entre la morfología, la semántica y la pragmática}

Desde el punto de vista terminológico, la communis opinio lingüística admite la definición del diminutivo como «une unité lexicale, une formation ou un morphème qui exprime la petitesse» (Debowiak, 2014: 16). Sin embargo, más allá de esta noción básica de la expresión de pequeñez, el diminutivo expresa toda una serie de valores semánticos adicionales relacionados con la matización afectiva del enunciado por parte del emisor. Como señala Debowiak (2014: 17), los matices afectivos expresados por un diminutivo dependen, más que del tamaño factual del referente, de la naturaleza del referente mismo. Si bien es cierto que los diminutivos suelen expresar (desde el punto de vista tipológico) connotaciones más bien positivas ${ }^{1}$, el abanico de posibilidades de expresión afectiva es muy variado: «En general, le sens évaluatif d'un diminutif donné ne se comprend correctement que dans le context, à l'aide d'indices prosodiques, comme l'intonation, ou extralinguistiques, comme la mimique, les gestes, etc.» (Debowiak, 2014: 18). En tal sentido, la cuestión de la comprensión contextual del sentido del diminutivo se revela como una dificultad teórico-metodológica considerable, habida cuenta de que el corpus lingüístico con el que trabajaremos es un texto literario, que, por definición, carece de rasgos prosódicos unívocos y no ofrece la posibilidad de verse acompañado de elementos extralingüísticos. No obstante, antes de abordar esta dificultad metodológica, es necesario apuntalar las cuestiones terminológicas y ofrecer una

\footnotetext{
I Además, en el terreno específicamente pragmático, «el uso de diminutivos se asocia tradicionalmente a la expresión de cortesía positiva», como señala Curcó (1998: 153).
} 
visión general interlingüística del uso de los diminutivos en alemán y en español.

Si atendemos a la tipología, el uso de los sufijos diminutivos es un rasgo que comparten numerosas lenguas de familias diferentes. Debowiak (2014: 18) sostiene que se trata de una categoría universal propia de prácticamente todas las lenguas del mundo. Además, en no pocas lenguas genéticamente inconexas los diminutivos sirven para expresar nociones pragmáticas ${ }^{2}$. No obstante, en el caso específico del alemán (en contraposición explícita al español), la comparación revela la gran diferencia existente entre estas dos lenguas en lo relativo al rédito lingüístico ofrecido por los diminutivos. Por una parte, el espectro de variedades morfológicas en la sufijación diminutiva en español es cuantitativamente mucho mayor ${ }^{3}$, además de que forma parte activa de la lengua usada en coordenadas diatópicas, diastráticas y diafásicas de índole muy diversa. Por otra parte, a esta mayor variedad morfológica corresponde una mayor gama de valores semánticos y pragmáticos ${ }^{4}$. A través de los ejemplos seleccionados veremos, pues, que desde el punto de vista cualitativo, los distintos matices semánticos/pragmáticos (como afecto, ironía, desprecio, atenuación retórica, intensificación, etc.) que se hallan implícitos en el uso de determinados sufijos diminutivos en español no son los mismos que en alemán. El motivo fundamental es que, si bien los sufijos diminutivos existen en alemán, su uso ha quedado reducido a expresiones lexicalizadas o bien tiene un valor semántico y/o pragmático mucho

2 Véase Mendoza (2005: 171).

3 Véase la clasificación de los sufijos diminutivos en español realizada por Debowiak (2014: 118-122). Véase asimismo Martín Zorraquino (2012: 127-130).

4 Tal y como demuestra Martín Zorraquino (2012), quien presta especial atención al uso de los diminutivos como estrategia de cortesía verbal. más limitado que en español. Más allá del valor hipocorístico (el rasgo que más claramente comparten el español y el alemán), el alemán no comparte con el español el uso del diminutivo para la expresión de nociones semánticas/pragmáticas que en español son esenciales, como, por ejemplo, la atenuación de un acto de habla ${ }^{5}$.

En el marco de estas consideraciones teóricometodológicas preliminares, es preciso atender al concepto de la morfopragmática, que, fundamentalmente en el caso de los ejemplos pertenecientes a las partes dialogadas, juega un papel importante. Mariottini (2006: 110) define el concepto del siguiente modo:

\begin{abstract}
El término morfopragmática se refiere al estudio de la información pragmática que conllevan ciertas clases de morfemas. Tanto la morfología derivacional como la flexiva son campos relevantes en la investigación morfopragmática, puesto que los hablantes hacen uso de estos dos recursos para producir diferentes tipos de efectos perlocutivos. La morfopragmática puede definirse como el área de la combinación de los significados pragmáticos con las reglas morfológicas, es decir, el área en la que una regla morfológica produce efectos pragmáticos regulares.
\end{abstract}

Por su parte, Dressler y Merlini Barbaresi (1994: esp. 84-169), señalan tres vertientes funcionales en el estudio de los diminutivos: en primer lugar, la denotativa, merced a la cual se expresa la noción semántica de lo «pequeño». En segundo lugar, la connotativa, que corresponde a los rasgos «emocionales» implícitos en los diminutivos. En tercer lugar, la pragmática, según la cual los actos comunicativos de los que forman parte los diminutivos adquieren el rasgo general de lo «no-serio». Esta distinción es importante para nuestros objetivos en la medida en

5 Como señala Waltereit (2006), apud Contreras (2012: 465). 
202 que el corpus textual examinado ofrece ejemplos de tres tipos diferentes: a) dotados de un valor funcional meramente denotativo; b) que presentan rasgos semánticos emocionales; c) con matices pragmáticos adicionales condicionados por el contexto comunicativo.

Desde el punto de vista estrictamente morfológico, nos centraremos esencialmente en los sufijos diminutivos -ito/-a e -illo/-illa. No solo se trata de los diminutivos que más recurrentemente aparecen en el corpus con el que trabajaremos, sino que, además, son los sufijos más productivos en español ${ }^{6}$.

Por otra parte, volviendo a la cuestión del contexto, nos topamos con el problema de que, metodológica y epistemológicamente, el corpus textual seleccionado, sin duda, condiciona las conclusiones del presente artículo, habida cuenta de que se trata de un texto literario. Si bien es cierto que las partes dialogadas tienen una amplia presencia en esta novela y que, por ende, el autor pretende reproducir el habla coloquial, deben valorarse con suma cautela las conclusiones sociolingüísticas de un análisis pragmático. El medio literario puede imitar, acaso, la lengua hablada «real». Sin embargo, se tratará en todo caso de una reproducción artificial, condicionada por las exigencias estéticas de la obra. Así pues, cualquier función pragmática, y especialmente aquellas relacionadas con la cortesía, deberán examinarse necesariamente con la debida conciencia de que, en el mejor de los casos, imitarán fenómenos pragmáticos de interacción social.

En tal sentido, resulta interesante evocar la teoría de los «actos de habla» de Searle (1975), para quien en el discurso literario y especialmente en el novelístico no hay auténticos actos de habla,

\footnotetext{
6 Cf. Debowiak (2014: 118-119). Véase asimismo Eddington (2002: 395-396), quien presta atención específicamente sobre el sufijo -ito/-a, por ser el más común.
}

sino «imitaciones» o «simulaciones» de actos de habla auténticos. En esta línea hermenéutica, el discurso ficcional de la novela es, pues, de acuerdo con Cofré (1991: 313), una consecuencia de «[e] 1 acto de pretender emitir actos ilocucionarios pero no realizarlos en realidad (en serio)». Con una postura análoga, Austin (1962: 22) excluye de su análisis de los actos de habla el discurso literario por considerarlo como un lenguaje «parasitario» en relación con el uso normal del lenguaje.

A pesar de que las limitaciones espaciales del presente trabajo no nos permiten abordar en profundidad esta compleja cuestión, la justificación de nuestros objetivos nos obliga a considerar aquellas posturas que, en contra de la opinión de Austin (1962) y Searle (1975), tienen en cuenta la validez del lenguaje ficcional como sede de actos de habla. Así, nos parece adecuado optar por una postura metodológica ecléctica, y admitir, siguiendo la línea de Ohmann (1971) e Iser (1971: esp. 60-61), que, pese a que los actos de habla de la literatura ficcional no tienen una fuerza ilocucionaria real, se atienen a los principios que regulan los actos de habla reales, por lo que se consideran, en palabras de Ohmann (1971: 14-17) «quasi-speech acts»:

[T] he writer pretends to report discourse and the reader accepts the pretense. Specifically, the reader constructs (imagines) a speaker and a set of circumstances to accompany the quasi-speechact, and makes it felicitous (or infelicitous, for there are unreliable narrators, etc.) [...] A literary work is a discourse whose sentences lack the illocutionary forces that would normally attach to them. Its illocutionary force is mimetic. [...]. The reader may well attend them [i.e., the quasi-speech-acts] in a non-pragmatic way, and thus allow them to realize their emotive potential. In other words, the suspension of normal illocutionary forces tends to shift a reader's attention to the locutionary acts themselves and to their perlocutionary effects. 
La consecuencia de estas premisas teóricas es que debemos establecer una división bipartita en relación con la idiosincrasia ilocucionaria de los distintos tipos de discurso en el seno de la novela que configura el corpus textual a examinar: diálogo y partes narradas. En el primer caso aceptaremos que, pese a su naturaleza miméticoficcional, existe una transacción entre los interlocutores que condiciona sus relaciones (lo que supone el fundamento de los actos de habla), y que, por tanto, estamos en condiciones de analizar los diálogos en los mismos términos en los que lo haríamos si se tratase de actos ilocucionarios reales. En el caso de las partes narradas asumiremos que se produce una marcada suspensión de la fuerza ilocucionaria del acto de habla, por lo que queda descartado un análisis de las estrategias de cortesía en estos pasajes, en la medida en que la cortesía per se es, como señala Níkleva (2011: 64), un fenómeno sociopragmático operativo entre la instancia del emisor y su(s) interlocutor(es) destinado a mantener un equilibrio entre una y otra parte de esta transacción comunicativa ${ }^{7}$.

Dado que no nos hallamos ante un contexto comunicativo donde entra en conflicto directo el face de sus interlocutores (ya que uno de ellos es el narrador heterodiegético y el otro es el lector) queda excluido el examen de la vertiente pragmática de las estrategias de cortesía inherentes en el uso de los diminutivos en las partes narradas. Ahora bien, esto no significa que la palabra narrada no sea un acto comunicativo. Como señalábamos anteriormente, la consideración de los actos de habla de la lengua literaria como «quasi-speech-acts» (Ohlmann, 1975: 14-17) re-

7 Véase Brown y Levinson (1987: esp. 61ss.) en relación el modelo de equilibrio entre la imagen (face) positiva y negativa de los interlocutores de un acto de habla como fundamento de la cortesía verbal. suelve la aporía de la comunicación efectiva entre la instancia del emisor y el receptor del discurso literario. Pese a que el narrador y el lector no pueden considerarse interlocutores que participan en un acto de habla normal, los actos de habla sui generis del narrador pretenden alcanzar un efecto determinado en el lector, esto es, están dotados de un valor quasi-perlocutivo ${ }^{8}$. Así se entiende que, como veremos, el autor usa en algunas ocasiones los sufijos diminutivos como recurso destinado a crear ironía o bien los dota de un valor peyorativo o despectivo.

Se trata, pues, de casos en los que el emisor del mensaje (en este caso, la instancia discursiva del narrador) pretende conferir a la expresión o al término en cuestión un valor pragmático adicional al inherente en la semántica del término, más allá del uso denotativo de aminoramiento, que es el valor primario de los diminutivos en español.

La diferencia en términos pragmáticos entre diálogos y partes narradas responde a cuestiones de orden teórico que es necesario definir de manera preliminar. Ahora bien, desde el punto de vista organizativo, esta división no afectará a la disposición de nuestros argumentos, ya que optaremos por un procedimiento de análisis predominantemente inductivo. Esto es, nuestro modus operandi consistirá en pasar de la realidad lingüística (en nuestro caso, de los ejemplos concretos del corpus textual analizado) a la teoría, y no a la inversa. En todo caso, como veremos, la mayor parte de los usos pragmáticamente neutros de los diminutivos se concentra en las partes narradas, por tratarse de un discur-

8 Véase Austin (1962: esp. 94-113) y Searle (1969: esp. 2226) en relación con las modalidades de transacción en los actos de habla (locución, ilocución y perlocución), así como Linke - Nussbaumer- Portmann (1991: esp. 182-195). 
204 so más objetivo y descriptivo, mientras que los casos en los que pueden apreciarse matizaciones pragmáticas se insertan mayoritariamente en las partes dialogadas.

Por otra parte, la clasificación de Mendoza (2005) en cuanto al uso de los diminutivos en español servirá asimismo de orientación metodológica. La autora distingue dos grandes categorías, a saber, los usos morfopragmáticos y los usos morfosemánticos de los diminutivos. En el primer caso, Mendoza se centra fundamentalmente en el valor de estos afijos como atenuadores retóricos, mientras que en el segundo grupo establece, a su vez, una subdivisión entre diminutivos hipocorísticos y diminutivos de aproximación.

No obstante, esta clasificación servirá como guía terminológica, más que como fundamento teórico sistemático, ya que, tal y como se desprende de los argumentos de Dressler y Merlini Barbaresi (1994), la distinción entre usos morfosemánticos y usos morfopragmáticos está fuertemente condicionada por aspectos contextuales ${ }^{9}$. Así, por ejemplo, no es posible decidir si un diminutivo funciona como expresión de cortesía o como mero sufijo pragmáticamente neutro que denota pequeñez si no se halla inserto en un contexto conversacional concreto (e incluso en estos casos pueden darse divergencias interpretativas).

Las categorías establecidas por Mendoza (2005) son, pues, solo una clasificación de referencia, no compartimentos estancos. En consecuencia, numerosos ejemplos de diminutivos que se hallan en nuestro corpus textual o bien no pueden adscribirse a ninguna de las categorías establecidas por la autora, o bien son susceptibles de asignarse a más de una categoría a la vez.

9 Véase también, en tal sentido, Mariottini (2006:107-108).

\subsection{La traducción de los diminutivos}

La gran dificultad que entraña la traducción de diminutivos radica en su naturaleza misma: se trata de afijos derivativos que expresan aminoración y cuyo valor predominante es, como acertadamente defiende Hummel (1997: 196-197) ${ }^{10}$, apreciativo:

Por esto los diminutivos son, y no en último término, especialmente apropiados para la expresión de la apreciación subjetiva, puesto que no establecen la apreciación en los nombres con la precisión de los adjetivos, sino que la realizan indirectamente a través del contexto y la situación. Al lector u oyente, frecuentemente, la apreciación le es tan solo sugerida sin despejarle la última duda. Cuando utiliza los diminutivos, el hablante opera conscientemente con su indeterminación, que él puede eliminar contextualmente de forma más o menos clara.

El uso de diminutivos que designan «objetivamente» la aminoración es, pues, sin duda, claramente secundario en relación con los usos en los que está presente una valoración subjetiva. Precisamente este hecho condiciona crucialmente la traducción de los diminutivos, puesto que en muchos casos el traductor se hallará ante la dificultad que surge de la indeterminación de los diminutivos y se verá obligado a decidir, en función del contexto y de su apreciación subjetiva, si el sufijo en cuestión designa meramente aminoración o bien si (y estos serán la mayoría de los casos) hay un componente de naturaleza emocional/afectiva. Si se da esta circunstancia, el traductor deberá, por último, interpretar qué tipo de noción afectiva prevalece. Esto no implica necesariamente transformar la indetermi-

\footnotetext{
Io Quien, a su vez, se basa en los postulados de Amado Alonso (1965 [=1931]) sobre los valores subjetivos de los diminutivos.
} 
nación del diminutivo en determinación, pues, precisamente en la traducción literaria es fundamental preservar la ambigüedad inherente al discurso literario ${ }^{11}$. Pero, aunque la traducción como producto mantenga la indeterminación, la traducción como proceso deberá tratar de desambiguar el valor o los valores denotativos predominantes en cada caso $^{12}$. En última instancia, esta observación entronca con la necesidad, según defiende Nord (1991: 79-81), de examinar la función del texto fuente como paso indispensable para la praxis traslaticia ${ }^{13}$.

\section{EXPOSICIÓN DE RESULTADOS}

Proponemos, pues, clasificar los diminutivos del corpus en cuestión conforme al siguiente esquema:

2.1. Diminutivos denotativos de «pequeñez»

2.2. Diminutivos hipocorísticos

2.3. Diminutivos con connotaciones irónicopeyorativas

2.4. Diminutivos de aproximación /atenuación retórica

II En otras palabras, por más que la traducción, como forma de lectura, aspire a encontrar $e l$ sentido de un texto literario, se debe ser consciente de que el texto literario nos sitúa ante una polivalencia de significados que le es intrínseca. Dicha indefinición del potencial semántico del texto literario debe ser respetada a toda costa por el traductor, tal y como defienden Hatim y Mason (1990: 11), quienes concluyen que «the translator 's task should be (...) not to reduce the dynamic role of the reader».

I2 En relación con dicha distinción entre proceso y producto traslaticio, véase Hatim y Mason (1990: 3-4), cuyo enfoque propone, en palabras de Hurtado Albir (1994: 36), «un análisis integrador del proceso discursivo del traductor (proceso y producto)».

I3 Lo que, a su vez, conducirá a una traducción instrumental o bien documental. Nos hallamos ante un problema (el de la necesidad de examinar y determinar la función del texto fuente y las consecuencias que de ella se derivan) que, como es sabido, no está exento de polémica y ha sido cuestionado por parte de algunos estudiosos, como, por ejemplo, Pym (1993: 184-185).
2.5. Diminutivos con valor intensificativo

2.6. Lexicalizaciones

\subsubsection{Hipocorísticos semilexicalizados}

\subsubsection{Pseudodiminutivos}

\subsection{Diminutivos denotativos de «pequeñez»}

A esta primera categoría corresponden la mayor parte de ejemplos del corpus seleccionado. Se trata de sufijos pragmáticamente neutros cuyo uso predominante es denotativo. El valor semántico que el sufijo añade al lexema es el de «tamaño pequeño». Como señalábamos antes, este uso de los diminutivos se da sobre todo en partes narrativas. Es más, ninguno de los ejemplos citados corresponde a partes dialogadas. A continuación, se enumeran los ejemplos que corresponden a esta categoría ${ }^{14}$ :

- una ligera brisa estremece el techo de papelitos y le arranca un rumor fresco de cañaveral. (5) // Eine sanfte Brise lässt das papierne Dach erzittern (10)

- daba saltitos (19) // er herumhüpfte (38)

- sombreritos (25) // Sonnenhütchen (51)

- saloncito $(84,94,98,116,190) / /$ kleiner Besucherzimmer (169); kleiner Raum (190); Vorzimmer (196); Nebenzimmer (231); Zimmer (389)

- perrito $(128,166) / /$ Hündchen $(56)$; Hund (335)

- granito $(130,155,199) / /$ Sandkörnchen $(262,315,409)$

- sobrinitos (134) // Kinder (269)

- librito (143) // kleines Buch (287)

${ }^{14}$ En lo sucesivo se usará para las citas procedentes del corpus textual seleccionado las versiones en español y en alemán, con el número de página de la edición respectiva (en paréntesis tras la cita). 
- gatito $(161,176) / /$ Kätzchen $(327,356)$

- ojitos $(166,195) / /$ kleine Augen $(335,399)$

- traserito (176) // kleinen ... Hinterteil (356)

- manita (37, 175, 176) // kleine Hand (355, 356); winzige Hand (74)

- trotecillo (122, 123, 178) // Tappen (245); Trippeln (247); Tapsen (362)

- palitos (183) // Geröll (373)

- jarritos (183) // kleinen Tonkrügen (373)

- pajaritos (183) // Vögelchen (373)

- lacitos (208) // kleine Schleifen (429)

- con su poquito de alcohol (214) // mit seinem Tröpfchen Alkohol (440)

- mesita (7, 25, 27, 29, 110, 188, 197, 205, 207) // Tisch (14, 220); Nachttisch (53, 58, 426); kleiner Tisch (383); kleines Tischchen (403, 423)

- soltó una risita $(10,46,131,158,166,183) / /$ lachte kurz auf (19); sie kicherte nervös (263); Kichern (321); Grinsen (92); Gekicher (337); Lachen (372)

- casita(s) (13, 14, 37, 77, 134) // Häuschen (26, 27, 29, 269); Häuser (73), kleines Haus (155)

- callecitas $(14,37)$ // Gässchen (29); Gassen (73)

- novelita(s) $(27,155)$ // Liebesroman (53); Romanheftchen (355)

- ventanita $(41,42) / /$ kleines Fenster $(82,83)$

- francesita $(42,55) / /$ kleine Französin $(83$, 112)

- criadita $(44,45,54,82)$ // kleines Dienstmädchen (89); Dienstmädchen (90, 109, 167)

- hermanita (81) // kleine Schwester (165)

- cabecita(s) (82, 90, 93, 140, 147, 178) // Köpfchen $(165,281,362)$; kleine Köpfe (182, 188); Köpfe (295)
- boquita (85) // Mündchen (171)

- muchachita $(106,107,120,143,201)$ // Mädchen (211, 241, 287, 414); kleines Mädchen (213)

- perrita $(123,124,125)$ // Hündin $(246,248$, 251)

- la más bajita (123) // die kleinere (247)

- caritas de niños (133) // Kindergesichter (267)

- copita (170) // Gläschen (345)

- hijita (198) // Töchterchen (404)

- polvillo $(7,38,42)$ // Strahl (14); Staubpartikel (75); Staub (84)

- nubecilla (101, 102, 133) // Wölkchen (204, 267); kleine Wolke (204)

- pelusilla $(109,118,143)$ // Flaum $(217,286)$; Fasern (237)

- arenilla $(175,196) / /$ feiner Sand $(355)$; Sand (402)

- estatuilla (201) // kleine Statue (414)

- cancioncilla de súplica (202) // Bittlied (417)

- florecillas (206) // Blumenblätter (423)

- cofrecillo (31) // Schmuckkästchen (62)

- piececillo (55) // Füsschen (110)

- pajarillo (60) //Vogel (215)

- diablillos (119) // kleine Teufel (237)

- ojillos (122) // Augen (245)

- pececillo (158) // kleiner Fisch (321)

- ojillos (165) // kleine Augen (333)

De los ejemplos citados pueden extraerse las siguientes conclusiones: por una parte, desde una perspectiva interna del funcionamiento del español, debe matizarse que es muy difícil determinar con absoluta seguridad en qué medida se trata de un diminutivo exclusivamente denotativo o si tiene un matiz emocional (afec- 
tivo-familiar) adicional. Se deberá convenir en todo caso en que solo puede hablarse de valores predominantes, sin que ello excluya la posibilidad de que la intención del autor (el emisor del discurso) diverja de la interpretación del lector-receptor. La ambigüedad de la intencionalidad autorial inherente a toda obra literaria se extiende, pues, también a este ámbito de interpretación lingüística. Algunos ejemplos que corroboran dicha ambigüedad son granito, risita, ojitos, traserito, novelita, francesita, criadita, muchachita, polvillo, pelusilla o arenilla, donde la aminoración objetiva se ve matizada por un componente apreciativo en una proporción imposible de cuantificar. En algunos casos la disminución objetiva desafía incluso las leyes de la lógica. A título de ejemplo, hablar de * polvo pequeño o de * grano de arena pequeño no difiere sustancialmente de algunos ejemplos que Hummel (1997: 197) califica de «agramaticales», como *año u *hora pequeña (a partir de añito u horita). No obstante, insistimos, nuestra clasificación no pretende establecer categorías impermeables, pues, como vemos, hay numerosos ejemplos de diminutivos que pueden adscribirse a más de una categoría a la vez.

Por otra parte, desde el punto de vista translingüístico, se observa que la traductora opta en gran parte de las ocasiones por verter el término con diminutivo al alemán a través de la fórmula «kleine $(r)(s) . . . »$; en otras ocasiones en la versión alemana aparece el sufijo diminutivo -chen en alemán, si bien este último caso ofrece un rendimiento lingüístico más limitado, ya que, como señalábamos anteriormente, el alemán es mucho menos prolífico que el español en el uso de diminutivos. En los casos en los que la autora no recurre al diminutivo en alemán (que son la mayoría), los motivos son de índole diversa: en unos casos puede retrotraerse a motivos de uso. Así, por ejemplo, la expresión *Schwesterchen o
*Schwesterlein —como traducción de la palabra hermanita- está más bien en desuso en el alemán actual o bien tiene connotaciones semánticas distintas de las que tiene el término en español. En otros casos la motivación es de índole puramente morfológica: por ejemplo, para perrita no cabe la posibilidad de usar el diminutivo Hündchen en alemán si no quiere convertirse el género sexualmente femenino del español en epiceno. Por último, la elección estilística también desempeña un papel relevante como condicionante para la opción traslaticia. Este es el caso en Bittlied para cancioncilla o Blumenblätter para florecillas: en estos ejemplos y en otros análogos, la traductora evita añadir, por motivos aparentemente estilísticos, un sufijo diminutivo e incluso un adjetivo que refleje la semántica hipocorística o la mera denotación de pequeñez del adjetivo en español.

\subsection{Diminutivos hipocorísticos}

En ocasiones, además del valor que denota pequeñez, se dan casos en los que el diminutivo añade una connotación que expresa matices relacionados con la familiaridad, la intimidad y el afecto. Para Mendoza (2005: 165), se trata de uno de los usos más comunes de los diminutivos no solo en español sino también en otras lenguas románicas y también en alemán. A continuación, se enumeran aquellos ejemplos, que, atendiendo a motivos contextuales y de uso del español, pueden considerarse como pertenecientes a esta categoría:

- parejita (122) // Pärchen (244)

- chiquilla /-o(s) $(14,15,54,56,60,77,88 ; 90$, $93,106,113,130,167,168,179,209) / /$ kleine(r) Junge(n) (178, 227, 404); Kinder (181); Bengel (29); Gören (29); Kleinen (110, 364); Kleine (114); Junge (122); kleines Mädchen (155, 
208

188, 212, 246, 339); Mädchen (262); Liebling (339), du Süsse (342); meine Liebste (431). En este caso el contexto se revela como un condicionante decisivo a la hora de asignar al término chiquillo /- $a$ un valor meramente denotativo (como designación de juventud/ pequeñez de un muchacho/-a) o bien un tono afectivo-familiar que va más allá de la denotación de pequeñez. Como se desprende de los ejemplos citados, en unas ocasiones la traductora opta por un término más neutro desde el punto de vista de la expresión de afecto (p.e. Kinder, Junge, Mädchen), mientras que en otras usa un término dotado de un matiz adicional de afectividad (p.e. Liebling, meine Liebste o du Süsse).

- jovencitos /-as (7, 47, 137) // junge Männer (94) junge Mädchen (13); sehr jung (274). El matiz afectivo que otorga el sufijo diminutivo no se ve reflejado en la traducción alemana. Tan solo en el último caso (sehr jung) la traductora añade el adverbio sehr como una manera de intensificar la semántica de «juventud» inherente al adjetivo.

- amiguito (106) // ihr lieber kleiner Freund (212): en este caso la traducción trata de reproducir el matiz afectivo en el uso hipocorístico del término amigo, al mismo tiempo que capta la sutil alusión irónica del término amiguito en su contexto.

- el niño corría hacia ellos desnudito (178) // der Kleine lief nackig auf sie zu (362): el uso hipocorístico refleja afecto, intimidad, familiaridad. Mendoza (2005: 165) señala que también en alemán se da este valor connotativo. La particularidad del español radica, sin embargo, en que no solo admite la adición de sufijos diminutivos a los sustantivos, sino también a los adjetivos e incluso a verbos y adverbios. El alemán, por el con- trario, tiene un uso mucho más limitado en tal sentido ${ }^{15}$. Esta peculiaridad impide a la traductora, en este caso concreto, el reflejo exacto de todo el valor hipocorístico-afectivo de la expresión obtenido a través del sufijo diminutivo del adjetivo desnudito. Podemos aventurar que la traductora, consciente de esta dificultad, ha pretendido compensar la pérdida del matiz afectivo a través de la traducción de niño como der Kleine (en vez de optar por una traducción más neutra como sería *das Kind o *der Junge ${ }^{16}$. Si aceptamos esta hipótesis, la traductora rubrica la notable sensibilidad estilística que demuestra en otros pasajes a la hora de enfrentarse a este tipo de retos traslaticios.

- De vez en cuando llamaba a los niños para limpiarles los moquitos (179) // ... Rotznasen (364): de manera similar al ejemplo anterior, el diminutivo refleja el uso hipocorístico como expresión de intimidad, afecto, familiaridad. Este uso es recurrente en varios ejemplos a lo largo del libro en casos en los que específicamente se habla de niños ${ }^{17}$.

- barriguita (81) // Bäuchlein (165): en este caso la traducción también usa el diminutivo, dado que el sufijo tiene aquí un valor hipocorístico que expresa familiaridad e intimidad, algo que el sufijo -lein en alemán también refleja.

- Me estás resultando un burguesito (183) // du wirst mir noch ein kleiner Burgeois (372): el contexto permite determinar que también

${ }^{15}$ Véase Dressler y Merlini (1994: 105).

${ }^{16}$ En relación con la técnica de la compensación en el ámbito de la traductología, véase Newmark (1991: 143-144) y Hurtado Albir (2001: 258, 270 y 634), quien, a su vez, coincide en parte con los resultados de Vinay y Darbelnet (1958).

${ }^{17}$ Estos casos de diminutivos pertenecerían a la categoría de lo que Dressler y Merlini (1994: 147) denominan el diminutivum puerile. 
en este ejemplo el diminutivo responde a un uso hipocorístico con valor afectivo.

- Marujita (60, 80, 93) // Marujita (122, 162, 188).

- Teresita $(66,73) / /$ Teresita $(135,149)$; o bien Teresina $(165,178) / /$ Teresina $(334,368)$. En este tipo de casos en los que se usa el diminutivo con un nombre propio de persona el valor connotativo de intimidad/familiaridad/afecto es el más usual (salvo que exista un deliberado matiz irónico-despectivo, que solo puede determinarse a partir del contexto; como veremos más adelante, nuestro corpus textual también incorpora ejemplos de este último tipo).

- viejecitas (62) // alte Damen (125)

- era una deliciosa mujercita pálida (184) // Sie war eine reizende, blasse und zierliche Frau (375). En este caso la traductora resuelve a través del recurso estilístico de la hendíadis la connotación afectiva del diminutivo. El valor positivo del sufijo se expresa a través de la adición del adjetivo zierlich, que no aparece como tal en el texto original español.

- calorcillo (80) // Wärme (163): el matiz de afectividad/sensualidad que el diminutivo añade al término calor no se ve reflejado en la traducción.

A partir de los ejemplos citados se reafirma, por una parte, la observación llevada a cabo supra, a saber: solo el contexto permite discernir si existe o no una connotación emocional. Por otra parte, como se desprende de los ejemplos, la traductora opta por recursos diversos a la hora de plasmar en el texto alemán los matices afectivos de los diminutivos en español. Para abordar esta dificultad no existe una fórmula polivalente, de modo que los recursos morfoestilísticos son variados. No obstante, la versión en alemán no siempre logra reflejar diversos matices connotativos del original español. Así ocurre en el último ejemplo citado (calorcillo // Wärme).

\subsection{Diminutivos con connotaciones irónicas o peyorativas}

Mendoza (2005: 163-164) menciona, pero no examina a fondo, una categoría semántica de los diminutivos que en español, y, en concreto, en el corpus textual analizado, tiene una importancia notable: el uso de los diminutivos como recurso destinado a crear ironía, o bien dotados de un valor peyorativo o despectivo. En efecto, tal y como señalan Márquez Reiter y Placencia (2005: 208), en el español peninsular no es infrecuente la asociación de los diminutivos con matices negativos o irónicos (frente a lo que ocurre en otras variantes del español, donde los diminutivos sí se usan con mayor frecuencia como atenuantes retóricos en contextos de cortesía verbal). A continuación, se enumeran y comentan los ejemplos correspondientes a esta categoría:

- desnudita (175) // nackig (356): a diferencia del ejemplo anteriormente citado bajo la categoría de hipocorísticos con matices afectivos (el niño corría hacia ellos desnudito) el adjetivo en este caso concreto no se halla inserto en un contexto que evoca afectividad infantil, sino que es más bien una alusión sexual. Por esta razón, el diminutivo no puede adscribirse bajo la categoría de hipocorístico afectivo, sino que más bien está dotado de un cierto matiz irónico-despectivo.

- Esperaba la llegada de los tres señoritos (10) // er wartete darauf, dass die drei señoritos auf ihn zukämen (19). 
210 La palabra señoritos tiene una carga semántica que va más allá de su uso denotativo básico (señorito como diminutivo de señor). El uso del término señorito resulta interesante, ya que, tal y como señala Stoll (2006: 82): «se utiliza, sobre todo, en sentido irónico y despectivo para denominar a un joven de familia acomodada que lleva una vida ociosa o a alguien que intenta lo segundo sin contar con la primera condición». En este caso particular, resulta interesante observar que la traductora lo deja tal cual y opta por explicar su significado en una nota final (en un breve apéndice donde se definen algunos términos de realia que la traductora reproduce en su texto alemán sin traducirlos; en el caso de señorito la traductora reseña: «junger Mann aus reicher Familie» (444).

Al margen del valor denotativo primario, solo el contexto nos permite distinguir si su uso encierra un matiz peyorativo y/o irónico. La decisión de la traductora de usar la palabra señoritos tal cual en su traducción es adecuada, si bien implica que una parte, difícilmente cuantificable, de la connotación negativa de la palabra señorito en español se pierde en la traducción (o, en este caso, en la no traducción del término). Al margen de otros ejemplos análogos del uso de señoritos $^{18}$, en la página 70 (nosotros, los señoritos) nos hallamos ante un caso particular, pues la traductora opta por verter el término al alemán como wir Bürgersöhne (143). Resulta interesante comprobar a través de la traducción cómo el valor semántico/pragmático de un mismo sustantivo con el mismo sufijo puede variar en función del contexto en el que es usado. En este caso, la particularidad que lo distingue de la mayor parte de los usos de señoritos a lo largo de la novela

${ }^{18}$ Véase: p. 11 (traducción, p. 22: «die señoritos»); p. 21 (trad., p. 43 idem); p. 46 (trad., p. 92 idem); p. 56 (trad., p. 114 idem); p. 77 (trad., p. 157 idem); p. 102-3 (trad. p. 206 idem); p. 151 (trad. p. 307 idem). es que es Luis, uno de los jóvenes que, desde una perspectiva heterodiegética, pertenece a la categoría de «joven burgués», quien se denomina a sí mismo señorito. La autoironía implícita en el uso contextualizado del término implica que el matiz peyorativo externo, por así decir, no ha lugar. Luis asume el apelativo señorito, que en otros contextos se ve impuesto a determinados personajes por un narrador omnisciente que se erige en «portavoz» de una colectividad socioeconómica. Pese a que el término es el mismo, tiene lugar un cambio semántico/pragmático consistente en la sustitución del valor peyorativo externo por la autoironía. Con gran acierto, la traductora refleja esta modificación lingüística y opta por la traducción alternativa de Bürgersöhne. En la página 148 hallamos un ejemplo similar: en el contexto de un pasaje narrado, el término señoritos es traducido como reiche Bürgerkinder (300).

Otro caso interesante se halla en la página 70. Teresa denomina a Luis señorito sabelotodo, lo que es traducido como du Alleswisser (142). La traductora interpreta adecuadamente que en este caso no predominan las connotaciones socioeconómicas del término (como sí ocurre en la mayor parte de los casos en los que se usa este término), sino que responde a un uso hipocorístico. Dado el tono afectivo que se desprende del contexto, el ejemplo podría igualmente incluirse en la categoría que hemos examinado anteriormente en el punto 2.2 .

Resulta interesante observar cómo el caso de la palabra señorita difiere en relación con la versión masculina del término. Mientras señorito está dotado, en la mayor parte de las ocasiones, de un cierto matiz peyorativo, tanto en virtud de su lexicalización como del uso contextual concreto que se da en algunos de los pasajes anteriormente señalados, la palabra señorita no tiene un valor peyorativo por sí misma. En este caso, el 
diminutivo tan solo añade la noción (sutilmente hipocorística) de «juventud» en relación con el término señora. Significativamente, la traductora opta por conservar el término tal cual, sin traducción: Ein schönes Schauspiel für eine Señorita! (42) (¡Vaya espectáculo para una señorita! [21]). De esta manera, la traducción conserva el valor denotativo primario de la expresión en español, renunciando a usar el diminutivo en alemán *Fräulein, en cuyo caso el término habría quedado dotado de un matiz semántico levemente peyorativo ausente en el texto original.

No menos reseñable resulta el hecho de que se mantenga en la traducción el término español «Señorita» con la mayúscula alemana, mientras que en casi todos los casos de «señoritos» se emplea el término en minúscula y en cursiva. La única excepción la constituye el ejemplo de la página 56 (trad. p. 114), donde aparece en mayúscula y en letra redonda. A pesar de que pueda parecer una inconsecuencia, la decisión de la traductora no es, creemos, arbitraria: mientras que «señorito» aparece consignado en el glosario final (y, por tanto, debe entenderse como un término de realia, que, en consecuencia, es adecuadamente transcrito en cursiva, al igual que ocurre con los otros términos del glosario), la traductora considera la palabra «Señorita» como una mera fórmula de tratamiento lo suficientemente conocida para un lector alemán como para no tener que traducirla. Lo mismo ocurre con el único ejemplo de «Señorito» en mayúscula y letra redonda, que, en el contexto en el que se inserta, es meramente una fórmula de tratamiento sin connotación despectiva. La decisión, como vemos, es coherente, aunque no por ello menos discutible, pues, entre otras consecuencias que se derivan de ella, el texto alemán produce un efecto exotizante (una opción que, en última instancia, siempre es susceptible de crítica o de interpretación alternativa ${ }^{19}$ ).

Otros ejemplos de diminutivos con connotaciones irónicas o peyorativas son:

- El Pijoaparte no hizo caso del letrero que advertía: Camino particular. Prohibido el paso. — iA la mierda con sus letreritos! —exclamó- (16) // ... Scheiss auf ihre Schilder (31).

- ¡Vaya nombrecito! (29) // Blöder Name! (58) Mientras que en el caso de letreritos la connotación peyorativa del sufijo no se ve completamente reflejada en la versión en alemán, en este caso, la traducción sí plasma la semántica despectiva del diminutivo nombrecito.

- empleadillo (34) // kleiner Angestellter (66): en este caso la versión en alemán no reproduce toda la gama de matices irónicodespectivos del término, pese a que con la adición del adjetivo kleiner se logra aludir en parte a la semántica de «poca importancia» inherente al sufijo en este contexto.

- con putilla $(29,126,198)$, traducido al alemán como kleine Nutte $(66,406)$, o bien simplemente Nutte (253), nos hallamos ante una situación semejante a la del punto anterior. Aquí también el sufijo -illo (que, en principio, solo denota aminoramiento) adquiere un valor adicional peyorativo (lo pequeño se convierte en insignificante y, por tanto, digno de desprecio [Mendoza, 2005: 164]). Algo similar ocurre en el caso de Ricar-

I9 Nos hallamos, así, ante la consabida dicotomía entre traducción documental o instrumental, según defiende Nord (1991: 79-81). Para la oposición entre las estrategias, respectivamente, exotizante y naturalizante, véase asimismo Venuti (2012: esp. 157, 160-163), así como Holmes (2004: esp. 47ss.), cuyas teorías al respecto no se restringen a la poesía, sino que son extensibles al lenguaje literario en general. 
dito Borrell (157 y 160), que se mantiene tal cual en la traducción al alemán (317 y 325).

- De manera análoga, cierto chulito fantasioso (65) es traducido al alemán como ein gewitzter Bengel $(132)^{20}$. El diminutivo añade una connotación despectiva al adjetivo chulo (adecuadamente reflejada por la traductora a través de la elección de la expresión Bengel), si bien el valor intensificativo también se halla presente en el término.

- jovencito (35) // Bürschchen (69): en este caso puede apreciarse un cierto tono peyorativo / despectivo. Este matiz se aprecia especialmente en la página 125: A ver, usted, jovencito, dígame: ¿conoce a esas chicas? // Sie, junger Mann, sagen Sie mir: Kennen Sie diese Mädchen? En la versión en español el diminutivo, más allá de la denotación de juventud, añade al término sin sufijo *joven un tono que intensifica el valor peyorativo/despectivo del término en un contexto en el que Teresa, la interlocutora de Manolo, adopta humorísticamente un tono paternalista-autoritario. Manolo ha recibido una incómoda visita de unas conocidas cuya inesperada presencia lo pone en un compromiso ante Teresa, por lo que, tras despacharlas, recibe en tono jocoso la admonitoria interrogación de Teresa. Es útil citar el pasaje en su integridad:

Y sin dejar de peinarse [Teresa], remedando graciosamente con la expresión y el tono cierto tipo de interrogatorio que debía serle familiar, bromeó apuntándole con el dedo-: A ver, usted, jovencito, dígame: ¿conoce a esas chicas?

La versión en alemán traduce el término como junger Mann, a través de la cual se evoca el tono

${ }^{20}$ Véase también el mismo uso p. 66 , con la misma traducción en p. 134. paternalista-autoritario del original en español, pero de un modo mucho más atenuado. En la página 159 nos hallamos de nuevo ante un caso similar, con la diferencia de que, en esta ocasión, la traductora sí opta por una versión que refleja claramente el matiz despectivo del sufijo: ein Grünschnabel (322).

- Vaya con Manolito (138) // Sieh mal an, der Manolito (277). El diminutivo aparentemente queda englobado en la categoría que Mendoza (2005: 165) considera como cortesía positiva que tiene por finalidad expresar aprecio o admiración. La versión en alemán no permite captar este matiz pragmático adicional, y menos aún refleja el tono irónico del original en español, pues el contexto evidencia que el supuesto tono de admiración implícito en el diminutivo es jocoso: lejos de estimar a Manolo, las palabras del Rey del Bugui (rival de Manolo) reflejan su desprecio hacia él. En la página 124, sin embargo, se emplea la forma con el diminutivo -illo (en la versión en alemán se mantiene tal cual: Manolillo). En este caso es de nuevo el contexto el factor que determina el matiz semántico predominante: aquí no nos hallamos ante un diminutivo con sentido irónico-peyorativo, sino afectivo, por lo que correspondería a la categoría que hemos examinado en el punto 1.2.

- ...total, que es un fastidio la fiestecita esa (49) // kurz und gut, dieses reizende Fest ist ein einziger Krampf (99). El valor peyorativo del diminutivo se ve reflejado en la traducción a través del uso irónico del adjetivo reizend.

- modistilla (50) // Lehrmädchen (102): la traducción al alemán no reproduce el tono despectivo-peyorativo del término con el sufijo diminutivo -illo/-a. 
- burguesita $(71,117,132,133)$ // bürgerliches Dummchen (144); Töchterchen aus bürgerlichem Hause (233); burgeoises Töchterchen (266); Bürgertöchterchen (266): la traductora plasma el matiz despectivo/ peyorativo del diminutivo a través de recursos morfológicos (el uso también en alemán del diminutivo con valor despectivo), o bien morfoléxicos (Dummchen).

- marquesita (173) // Marquise (351)

- secretillos (153) // kleine Geheimnisse (311). En ambos casos el matiz peyorativo/ despectivo del diminutivo no se ve plenamente reflejado en la traducción. En el caso de Marquise, la versión en alemán obvia por completo la semántica connotativa de la versión en español, mientras que, en el caso de kleine Geheimnisse, reproduce meramente el valor de aminoración propio del diminutivo.

\subsection{Diminutivos de aproximación / atenua- ción retórica}

Los diminutivos de aproximación son definidos por Mendoza (2005: 166) como «a way of attenuating the meaning of adjectives and adverbs ${ }^{21}$. En los ejemplos que citamos a continuación los diminutivos funcionan en su vertiente pragmática como «hedges», también conocidos como atenuadores retóricos ${ }^{22}$. El sufijo está destinado a mitigar o atenuar la fuerza ilocutiva del acto de habla, en un contexto comu-

\footnotetext{
2I Terminológicamente, es, pues, importante remarcar que nos adherimos al uso que hace Mendoza (2005) de esta categoría, ya que para otros autores el concepto de diminutivo aproximativo no tiene exactamente el mismo significado. Así, por ejemplo, Taylor (1989:144-149), «[lo] relaciona (...) con expresiones de cantidad en las que el valor exacto no es relevante y el hablante se excusa por ello» (Ruiz de Mendoza, 2000: 363).

22 Véase Poveda (2008: 114), donde se revisan otras denominaciones alternativas que en los estudios lingüísticos se han dado al recurso pragmalingüístico del «hedging».
}

nicativo de cortesía verbal en el que el emisor trata de no dañar la imagen positiva o negativa de su interlocutor ${ }^{23}$. Como señalábamos anteriormente, la posibilidad de realizar un análisis de estrategias de cortesía queda reducida a las partes dialogadas, donde nos hallamos ante una versión mimética de actos de habla reales ${ }^{24}$. El examen de la pragmática comunicativa es, pues, posible en estos casos.

- El primer ejemplo merece una cita completa del pasaje dialogado, con el fin de ilustrar el significado contextual del diminutivo:

— ¿Es que piensas dejarnos? — preguntó el Cardenal.

- No es eso, caray, ya te contaré.

- No hace falta, ya veo que tienes un plan. ¿Y por qué no lo has dicho antes, cabrito?

—Aún no he decidido nada. Por una temporadita a ti no te va ni te viene, quiero decir que no te hago falta, tienes otros negocios... (111)

“Du willst uns wohl verlassen?” fragte der Kardinal. "Darum geht es nicht, verdammt, ich erklär dir das noch."

"Ist nicht nötig, ich habe schon begriffen, dass du etwas planst. Warum hast du das nicht gleich gesagt, du Hund?"

"Noch hat sich nichts entschieden. Es ist ja gar nicht für lange, kann dir also egal sein, ich meine, du kommst auch ganz gut ohne mich aus, du hast ja noch andere Geschäfte...” (221-222)

El diminutivo temporadita se usa como mecanismo de atenuación retórica, pues no solo incide en la brevedad del espacio de

23 Para un marco teórico en relación con los principios de cortesía y los modos de evitar el daño a la imagen positiva o negativa del emisor o bien del receptor, véase Brown y Levinson (1987: esp. 61-70).

${ }^{24}$ O, en palabras de Ohmann (1971: 14-17), «quasi-speech acts». 
214

tiempo, sino en su insignificancia. El sufijo entra en la categoría de lo que Mendoza (2005: 166-171) considera un «hedge» metalingüístico, esto es, un elemento que modifica el contenido metalingüístico de un acto de habla ${ }^{25}$. El sufijo expresa la modificación no solo del sustantivo «temporada», sino del acto de habla completo. En este caso, nos hallamos ante dos actos de habla yuxtapuestos: la afirmación; y la excusa de dicha afirmación, que queda implícitamente calificada como insignificante y, por tanto, factible. En el contexto comunicativo, el emisor (Manolo) emite una petición indirecta (pide ausentarse durante un tiempo). Dado que la petición supone, desde un punto de vista pragmático, una amenaza para la imagen del interlocutor (un face threatening act, según la terminología de Brown y Levinson [1987: 66]), el diminutivo se usa como recurso destinado a no dañar la imagen de su interlocutor.

- No puede pasar nada, tontina, esa gente ni siquiera sabe lo que tiene, ni se enterarán... (59) // Es kann dich nichts passieren, du Dummerchen, diese Leute wissen doch nicht einmal, was sie besitzen, die werden bestimmt nichts merken. (120)

También en este caso el diminutivo sirve para atenuar el significado del adjetivo y puede adscribirse a la categoría de los diminutivos de aproximación. Como señala Mendoza (2005: 166), este uso se da particularmente en el caso de adjetivos con connotaciones negativas con el fin de miti-

25 Véase asimismo Fuentes (2010: 27-28), Monjour (2006: 32-33) y Moser (2006:110-111), quienes también consideran los diminutivos como recursos de atenuación de actos de habla percibidos como (potencialmente) descorteses para el oyente. gar eufemísticamente la fuerza peyorativa del adjetivo. Esto es, se trata de un tipo de «hedge» semántico. Al margen de ello, el contexto también permite apreciar una connotación afectiva en el diminutivo.

- Algo similar ocurre con fierecilla (200) / du kleines Biest (411), o bien bestezuela (200) // kleines Tierchen (411). Se trata de un diminutivo de aproximación a través del que se mitiga la fuerza peyorativa del adjetivo. También en este caso el contexto permite apreciar una connotación afectiva en el diminutivo.

Al margen de las cuestiones relacionadas con la perspectiva interna del español, se observa cómo, desde el punto de vista interlingüístico, la traductora trata de reflejar los valores semánticos y pragmáticos de los diminutivos. En el caso de tontina / Dummerchen, la traducción se sirve del sufijo diminutivo-chen, que, contextualmente, también puede funcionar como diminutivo de aproximación en alemán. En otros casos, como fierecilla / kleines Biest y bestezuela / kleines Tierchen, la traductora recurre a la perífrasis kleine(s) + adjetivo para reproducir la atenuación retórica implícita en el diminutivo en español. Finalmente, la dificultad de reproducir con exactitud toda la fuerza ilocutiva de un acto de habla al traducirlo a otra lengua se evidencia en el caso de por una temporadita, cuya traducción perifrástica (Es ist ja gar nicht für lange) no tiene la pregnancia y efectividad de la versión original en español y no logra plasmar (o, en el mejor de los casos, solo lo logra parcialmente) la atenuación retórica y el valor de cortesía inherente a la expresión en español. 


\subsection{Diminutivos con valor intensificativo}

El valor intensificativo de un diminutivo se da cuando el término sufijado (normalmente adjetivos o adverbios ${ }^{26}$ ) adquiere una semántica según la cual se realzan las cualidades inherentes a su semántica básica. Así, por ejemplo, Mendoza (2005: 164) cita el ejemplo de tempranito > muy temprano; o bien limpiecito > muy limpio. Nuestro corpus textual ofrece varios ejemplos que se adscriben a esta categoría:

- rojillos (125) // eine rote Bande (252): el diminutivo en este caso intensifica el valor despectivo del adjetivo «rojo» (entendido como símbolo de una ideología política de izquierdas). Secundariamente, puede percibirse un tono de familiaridad y/o cercanía. Se trata de toda una gama de matices que es difícil de reproducir en la traducción.

- estás liquidando la botella tú solito (70) // du machst die Flasche ja ganz alleine leer» (143): el uso del diminutivo responde a una voluntad por parte del interlocutor de intensificar el acto ilocutivo y acentuar que exclusivamente tú estás liquidando la botella. En este caso la traducción vierte perfectamente al alemán este valor a través de la adición del adverbio ganz. La traductora emplea este mismo recurso en otros casos similares de diminutivos intensificativos, como los que se citan a continuación:

- doblando las rodillas poquito a poquito (179) // ganz allmählich die Knie beugend (363).

- bajito (165) // [ein] ganz kleiner Kerl (333334).

- nuevecita (37) // ganz neu (74).

${ }^{26}$ Véase Ruiz de Mendoza (2000: 364), quien va más allá al afirmar que no se usa nunca con sustantivos.
- En otras ocasiones, la traductora opta por recursos alternativos para reproducir el matiz intensificativo del superlativo. Así, por ejemplo, la semántica intensificativa ( $\mathrm{y}$, secundariamente, también afectiva) de la pobrecilla (195), se ve reflejada en la versión en alemán a través del uso del superlativo: die Ärmste (399). En el caso de quietecita (179) // still und steif (363), la traducción intenta reflejar a través de la hendíadis «still und steif» el valor intensificativo del diminutivo.

- Sin embargo, en otros casos la connotación intensificativa desaparece al verse traducido al alemán, como en: nuestro sitio estaba en el rincón más oscurito del jardín (134) // Unser Platz war in der dunkelsten Ecke des Gartens (268); o bien en derechitas al Cardenal (39) // direkt zum Kardinal (77). En este último caso, se da la dificultad de que el término sufijado es un adverbio, una particularidad que existe en español, pero no en alemán, por lo que la reproducción del valor intensificativo del diminutivo todavía se hace más difícil.

\subsection{Lexicalizaciones}

\subsubsection{Hipocorísticos semilexicalizados}

En español existe un elenco relativamente amplio de palabras (por lo general sustantivos y, en menor medida, también adjetivos) con sufijos diminutivos que pueden considerarse como semilexicalizadas. Es decir, se trata de términos compuestos por un diminutivo que, en su origen, añade un valor hipocorístico al lexema, si bien su uso se ha consolidado en el uso lingüístico hasta tal punto que el diminutivo se percibe más como parte de un giro idiomático que como un sufijo hipocorístico propiamente independiente. Los ejemplos que Últimas tardes con Tere$s a$ ofrece son los siguientes: 
- no te hagas el angelito (111) // spiel mal nicht den Unschuldsengel (222).

- graciosos morritos (147) // drollige Schnuten (295).

- modosita (7) // brav (13).

- mosquita muerta $(78,131) / /$ du stilles Wasser (159, 262).

- braguita $(124,208) / /$ Slip $(249,429)$.

- varita mágica (149) // Zauberstab (302)

- farolillos $(5,6) / /$ Lampions $(9,11)$

Como se aprecia implícitamente a través de la traducción alemana, la conciencia lingüística del sentido hipocorístico de estos términos queda difuminada como consecuencia de su uso idiomático. De nuevo, la versión en alemán revela la dificultad de verter a otra lengua distinta del español esta gama de valores semánticos e idiomáticos. En todo caso, la traductora opta acertadamente por no reproducir en ninguno de los casos matices hipocorísticos en la versión alemana, conservando, así, fielmente el valor cercano a la lexicalización de los diminutivos en los ejemplos citados.

\subsubsection{Pseudodiminutivos}

Consideramos como pertenecientes a una categoría diferente de la anterior aquellos sustantivos que han sufrido una lexicalización completa. Pese a que su origen morfológico es un sufijo diminutivo, este tipo de términos (por ejemplo, calderilla, bolsillo o bordillo) han alcanzado un grado de lexicalización tal que la derivación semántica en relación con el término del que proceden prácticamente ha desaparecido de la conciencia lingüística del hablante. Frente a expresiones semilexicalizadas a nivel de uso lingüístico ${ }^{27}$, el

${ }^{27}$ Como es, por ejemplo, el caso del sustantivo braguitas (ver supra), que, por motivos eufemísticos, suele usarse con el sufijo diminutivo, sin que por ello se pierda la conciencia de su asociación con el lexema brag. fenómeno de la lexicalización completa se define como «proceso por el que determinados elementos con valor gramatical o derivativo adquieren valor léxico al perderse sus significaciones primarias» (Montero, 2008: 118). Como señala Debowiak (2014: 39-42), se trata de un fenómeno frecuente en las lenguas románicas:

[C]ertains diminutifs s'emploient avec une si grande fréquence et / ou dans des contextes si précis qu'ils finissent par fonctionner en tant qu'unités lexicales non marquées et stables dans le lexique d'une langue. Ils commencent alors à être enregistrés dans les dictionnaires comme des entrées autonomes avec des acceptions parfois complètement détachées de leur signification originelle [...] Alors, [...] ils ne doivent pas désigner des objets forcément petits.

La marcada lexicalización de este tipo de términos ha llevado a los lingüistas a referirse a ellos como «pseudodiminutivos», «quasi diminutivos» o bien «diminutivos absolutos», entre otras denominaciones al uso (Debowiak, 2014: 40). A menudo resulta difícil distinguir claramente entre estos falsos diminutivos y expresiones semilexicalizadas, como las que hemos visto en el punto 2.6.1. Sin duda el contexto es un factor a tener en cuenta; no menos lo es la conciencia lingüística del hablante y su percepción subjetiva de la distinción entre lo idiomático y lo lexicalmente consolidado. En tal sentido, la información aportada por los diccionarios tampoco es concluyente, ya que, como es sabido, los repositorios lexicográficos siempre van detrás de la lengua activa.

Probablemente el criterio de distinción más eficaz es examinar el grado de desvinculación semántica del pseudodiminutivo en relación con el lexema sobre el que se basa. El siguiente ejemplo es ilustrativo: la palabra bolsillo (168) no designa un bolso pequeño, sino que ha adquirido 
una semántica independiente. De entre los numerosos ejemplos que incorpora el corpus textual examinado, esta es una breve muestra:

- camisa de rayadillo con tirilla abrochada bajo la nuez (14) // bis oben zugeknöpftem Baumwollhemd (27)

- cabrito $(111,202) / /$ du Hund $(221,416)$

- no debía andarse con chiquitas (207) // [man müsse] Nägel mit Köpfen machen (425)

Pese a que, en algunos de estos casos (como cabrito, tirilla y chiquitas) el diccionario de la RAE los identifica como diminutivos de, respectivamente, cabro, tira y chica, la conciencia lingüística del usuario del español los distingue con claridad como términos que, desde el punto de vista semántico, son independientes del lexema sin sufijo.

Un último caso interesante es el que ofrece el término carajillo (168), que en la versión alemana aparece tal cual como carajillo (341), sin traducir. La traductora incorpora este término en el apéndice de términos de realia que no se traducen en el texto de la novela en alemán:

- carajillo / perfumado: Beide Ausdrücke bezeichnen einen Kaffee mit Anisschnaps. Manolo korrigiert Teresas vulgäre Redeweise (carajo: das männliche Glied) durch den feineren Ausdruck perfumado.

Aquí nos hallamos ante un interesante ejemplo de colisión de percepciones semánticas o bien un «conflicto lingüístico» relacionado con cuestiones de orden sociolingüístico. En el primer caso, puede entenderse que Teresa usa el término carajillo como término lexicalizado, esto es, no percibe la palabra como término compuesto del lexema caraj- más el sufijo diminutivo -illo, sino como una palabra semánticamente autónoma.
Sin embargo, también puede especularse con la posibilidad de que Teresa, una joven burguesa que quiere mezclarse con el «proletariado» y ve a Manolo como el arquetipo de esta clase social, lleva a cabo un intento espontáneo de integrarse también lingüísticamente en una clase social distinta a la suya a través de la reproducción de un rasgo de habla que podría considerarse como vulgar. Este intento resulta fallido, pues Manolo la «corrige», invitándola a usar un término más «fino» (perfumado [168 // 341]). Además, en un pasaje posterior, el hermano de Manolo se ríe de ella cuando esta pide en un bar un perfumado ${ }^{28}$. La risa del hermano de Manolo refleja, en cierto modo, la vacilación de Teresa entre el habla propia de su auténtica clase social (y las variedades diastráticas que, en consecuencia, se esperan de ella) y el registro lingüístico «obrero» que Teresa cree encarnado en Manolo y los suyos. En cualquier caso, en la versión en alemán no es posible apreciar este conflicto lingüístico (salvo con la ayuda de la nota de la traductora).

\section{CONCLUSIONES}

El análisis contrastivo de la función semántica y pragmática de los diminutivos en Últimas tardes con Teresa en su versión española y alemana nos ha permitido llegar a una serie de conclusiones que afectan a dos vertientes interpretativas. Por una parte, desde el punto de vista del funcionamiento interno de la lengua española, el uso de diminutivos permite la expresión de una amplia gama de valores semánticos y pragmáticos, desde la mera denotación de pequeñez hasta la expresión de intensificación y de connotaciones afec-

${ }^{28}$ «Sin saber muy bien lo que hacía, pidió un perfumado (lo cual provocó una cumplida carcajada del hermano de Manolo) al tiempo que interrogaba al muchacho con los ojos, aturdida, deprimida por lo que acababa de ocurrírsele» (171). 
218 tivas o irónico-peyorativas. Numerosos ejemplos del corpus textual han puesto de manifiesto, además, la importancia de los diminutivos como estrategias de atenuación retórica en contextos de cortesía verbal y, por último, se ha comprobado que el fenómeno de la lexicalización desempeña un papel notable en el uso de los diminutivos. En todo caso, el contexto es determinante a la hora de establecer la prevalencia de uno u otro matiz semántico y/o pragmático.

Por otra parte, la comparación entre la versión española y su traducción al alemán nos ha permitido ratificar la notable diferencia existente entre estas dos lenguas en lo relativo el rédito lingüístico de los diminutivos, ya que en la mayor parte de las ocasiones el uso de este sufijo en alemán no es funcionalmente válido o bien conlleva la adición de connotaciones de tipo estilístico o prosódico o bien semántico y pragmático intrínsecas a los diminutivos en alemán que a menudo divergen de las del español.

Ante tal dificultad, la traductora opta por estrategias de variada índole que, como hemos tenido ocasión de ver, logran reflejar en unos casos mejor que en otros la gama de valores (semánticos y pragmáticos o también estilísticos) propios del texto original. No obstante, de la traducción se desprende que las decisiones contextuales predominan sobre las fórmulas prefijadas a la hora de solventar los casos concretos en los que aparecen diminutivos. Un recorrido sumario por los numerosos casos examinados pone de manifiesto que la misma palabra con el mismo sufijo puede dar lugar a traducciones diferentes. A través del ejemplo de jovencitos (por citar solo uno de entre varios) se ha comprobado que el contexto es crucial: en unos casos se opta por una traducción, aparentemente, más neutra (junger Mann), mientras que en otros la solución traslaticia trata de reflejar las connotaciones (irónicas o peyora- tivas, o bien afectivas) inherentes al diminutivo (Grünschnabel / Bürschhen). A partir de este ejemplo ilustrativo pueden extraerse dos conclusiones que afectan a la praxis traslaticia: en primer lugar, no es posible aplicar una regla general que sea válida para todos los casos, por lo que es necesario el examen detenido de cada ejemplo en su contexto. En segundo lugar, es igualmente determinante la conciencia lingüística de la lengua meta: la sensibilidad de la traductora en relación con el uso de la lengua alemana queda patente al demostrar a través de su traducción que, por ejemplo, junger Mann puede, en ocasiones, denotar nociones paternalistas / autoritarias, pero en otras ocasiones puede designar meramente a un hombre joven. Por lo tanto, nuestro estudio viene a confirmar que, de un modo más o menos analítico, más o menos intuitivo, una labor concomitante a la traducción es el examen semántico y pragmático (y, por extensión, funcional) del texto fuente. Este proceso, a su vez, requiere y se ve complementado por la revisión semántica y pragmática de la solución propuesta en la lengua meta, en el marco global del análisis funcional del texto meta y de la determinación de su skopos, tal como postula Nord (1991: esp. 10 y 27ss.).

El desiderátum de toda traducción es que exista una equivalencia que abarque desde el nivel semántico hasta el pragmático e incluso estilístico entre ambas lenguas ${ }^{29}$. En el caso concreto de la traducción de diminutivos en

${ }^{29}$ En relación con el controvertido concepto de equivalencia y las variadas interpretaciones de las que ha sido objeto, véase Hurtado Albir (2001: esp. 203-223), quien la considera, en la línea de otros autores, «como un concepto relacional entre la traducción y el texto original que define la existencia de un vínculo entre ambos; esta relación se establece siempre en función de la situación comunicativa (...) y del contexto sociohistórico en que se desarrolla el acto traductor $\mathrm{y}$, por consiguiente, tiene un carácter relativo, dinámico y funcional» (Hurtado Albir, 2001: 209). 
textos literarios, el examen de las soluciones traslaticias nos permite aventurar que, al menos en relación con los diminutivos que denotan pequeñez (los más neutros desde el punto de vista pragmático e intercultural, y que, además, suelen hallarse en contextos de narración heterodiegética), la obtención de dicha equivalencia es menos compleja que en aquellos casos en los que el diminutivo connota nociones semánticas adicionales (generalmente afectivas) o bien pragmáticas que, per se, no son unívocas. Mientras los diminutivos en español ofrecen una amplia gama de posibilidades de matización semántica y pragmática, el alemán se ve obligado a expresar estos mismos valores a través de medios lingüísticos ( $\mathrm{y}$, en este caso, también estilísticos) alternativos.

Pese al carácter eminentemente descriptivo de nuestro trabajo, las estrategias de traducción examinadas dan pie a colegir cautelosamente algunas pautas a la hora de traducir al alemán diminutivos procedentes de textos literarios. Basándonos en la distinción tripartita en relación con el estudio de los diminutivos por parte de Dressler y Merlini Barbaresi (1994: esp. 84169), la vertiente funcional denotativa (expresión de la semántica de lo «pequeño») ofrece soluciones comparativamente menos complejas, como es la adición de un sufijo diminutivo en alemán (-chen o -lein), o el uso de la perífrasis kleine(r)(s) junto con el adjetivo correspondiente. No obstante, si el contexto prosódico o estilístico del texto meta lo requiere, y en función de una serie de aspectos contextuales en el seno del texto fuente (como, por ejemplo, el grado de lexicalización del término) será en ocasiones inevitable optar por soluciones traslaticias ad hoc.

La vertiente funcional connotativa, que da cuenta de los rasgos «emocionales» implícitos en los diminutivos, se halla en una escala de complejidad mayor. En estos casos la incorporación del sufijo diminutivo en alemán es una opción que puede funcionar en algunos casos, siempre y cuando se obtenga un efecto de familiaridad o afecto análogo al original. En los casos en los que esto no sea posible (por ejemplo, si el diminutivo afecta a un adjetivo), será preciso optar por estrategias de compensación estilística, como hemos visto a propósito de «el niño corría hacia ellos desnudito // der Kleine lief nackig auf sie zu».

Por último, la vertiente funcional pragmática representa, sin duda, el mayor desafío, ya que este tipo de casos está más fuertemente condicionado tanto por el contexto como por la propia apreciación subjetiva de los participantes del acto comunicativo (en este caso de la instancia del lector). A través de los diferentes usos del término señorito y de sus múltiples soluciones traslaticias hemos comprobado que el contexto es el único factor determinante. No puede colegirse una pauta de traducción universalmente válida, por lo que el traductor se verá enfrentado en cada caso particular con el reto de hallar una equivalencia en la que, en ocasiones, deberá respetarse la dimensión pragmática tanto como la semántica. Cuando la pragmática del diminutivo permita inferir usos irónicos o incluso humorísticos ${ }^{30}$ deberemos convenir con Attardo (2002: 175) en que, dado que la ironía y el humor se definen por sus efectos perlocutivos (dicho de un modo muy reductivo: pretenden hacer reir), será preciso anteponer, en ocasiones, la equivalencia pragmática sobre la semántica,

${ }^{\circ}$ Recordemos que, desde la perspectiva funcional pragmática, los actos comunicativos de los que forman parte los diminutivos adquieren el rasgo general de lo «no-serio», de acuerdo con Dressler y Merlini Barbaresi (1994: esp. 84-169). 
o, cuanto menos, equipararlas ${ }^{31}$. A título ilustrativo cabe recordar que la traductora opta en una ocasión por verter burguesita como bürgerliches Dummchen al alemán, a pesar de que la palabra ${ }^{*}$ tonta o ${ }^{*}$ tontina $^{32}$ no aparece en el texto original. El tono sutilmente irónico-humorístico motivado por la adición del sufijo diminutivo obliga a la traductora a buscar la equivalencia pragmática, a sabiendas de incurrir en una leve licencia semántica ${ }^{33}$.

Pese a las limitaciones inherentes a todo estudio de caso, nuestra contribución no solo ratifica la validez del concepto de morfopragmática (tal y como lo defienden Dressler y Merlini Barbaresi [1994]), sino que, además, demuestra que el análisis de la traducción de fenómenos que recorren transversalmente el terreno morfológico, estilís-

${ }^{31}$ Attardo (2002: 175) propone una definición de la traducción en la que se respete la fuerza pragmática del texto del mismo modo que su fuerza semántica: «a correspondence between two texts $\mathrm{T} 1$ and $\mathrm{T} 2$, such that the meaning (M) of T1 (MT1) and the meaning of T2 (MT2) are similar (approximate): MT1 $\approx$ MT2 and/or the pragmatic force (F) of T1 (FT1) and the pragmatic force of T2 (FT2) are similar/approximate: FT1 $\approx$ FT2». Es importante precisar en este punto que, como señala el propio autor (2002: 174), la distinción entre semántica y pragmática es meramente pedagógica, al menos en lo que respecta a las teorías del humor.

${ }^{32}$ Este término es usado por Marsé en otro pasaje de la novela (p. 59), que en la traducción alemana se traduce como Dummerchen (p.120).

${ }_{33}$ No obstante, es cierto que la elección del término Dummchen no es arbitraria, sino que se ve legitimada por el contexto, donde el término burrada justifica semánticamente la decisión de la traductora:

ES: «¿Será que no le gusto lo bastante, habré dicho alguna burrada de burguesita, de esas que él no puede soportar?» (p. 71).

$\mathrm{DE}$ : «Ob ich ihm wohl nicht gut genug gefalle, ob ich Unsinn geredet habe wie eines dieser bürgerlichen Dummchen, die er nicht ausstehen kann» (p. 144).

Como se ve, una vez más, la traductora pone de manifiesto su notable sensibilidad lingüística y estilística y su capacidad para discernir si el contexto exige dar prioridad a lo semántico o bien lo pragmático. tico y/o pragmático es un campo tan complejo como feraz. Las líneas de investigación, más allá de los diminutivos, se abren hacia el examen de otros afijos, elementos prosódicos y estilísticos cuyo análisis desde perspectivas traductológicas encierra, sin duda, un gran potencial.

\section{REFERENCIAS}

Alonso, Amado (1961) [1935]: Noción, emoción, acción y fantasía en los diminutivos, Madrid: Gredos.

ATtARDo, Salvatore (2002): «Translation and Humour», The Translator, 8/2, 173-194.

Austin, John Langshaw (1962): How to do things with words, Oxford: Clarendon Press.

Brown, Penelope y Stephen Levinson (1987): Politeness: Some universals in language usage, Cambridge: Cambridge University Press.

COFRÉ,Juan (1991): «La paradoja de la narración: de los actos de habla a los actos de conciencia», Revista de Filosofía, 6, 311-333.

Contreras FernándeZ, Josefa (2012): «¿Hay diferencias en las estrategias de atenuación usadas en los correos electrónicos españoles y alemanes?», en Julio Escamilla Morales y Henry Vega (eds.), Miradas multidisciplinares a los fenómenos de cortesía y descortesía en el mundo hispánico, Barranquilla: Universidad del Atlántico Programa EDICE, 451-471.

Curcó, Carmen (1998): «¿No me harías un favorcito? Reflexiones en torno a la expresión de la cortesía verbal en el español de México y el español peninsular», en Henk Haverkate, Gijs Mulder y Carolina Fraile Maldonado (eds.), La pragmática lingüística delespañol:recientes desarrollos, Ámsterdam: Rodopi, 129-171.

Debowiak, Przemyslaw (2014): La formation diminutive dans les langues romanes, Frankfurt: Peter Lang.

Dressler, Wolfgang y Lavinia Merlini Barbaresi (1994): Morphopragmatics: Diminutives and Intensifiers in Italian, German, and other languages, Berlín/ Nueva York: Mouton de Gruyter.

EDdington, David (2000): «Spanish diminutive formation without rules or constraints», <http://linguistics.byu.edu/faculty/eddingtond/diminutive.pdf>. 
Fuentes RodríGuez, Catalina (2010): La gramática de la cortesía en español/LE, Madrid: ArcoLibros.

Hatim, Basil e Ian Mason (1990): Discourse and the Translator, Londres/Nueva York: Longman.

HoLmes, James (1998): Translated! Papers on Literary Translation and Translation Studies, Ámsterdam: Rodopi.

Hurtado Albir, Amparo (2001): Traducción y Traductología, Madrid: Cátedra.

Hurtado Albir, Amparo (1994): «Perspectivas de los Estudios sobre la Traducción», en Amparo Hurtado Albir, Estudis sobre la traducció, Castellón: Servicio de Publicaciones de la Universitat Jaume I, 25-42.

Hummel, Martin (1997): «Para la lingüística de vuestro diminutivo: los diminutivos como apreciativos», Anuario de Estudios Filológicos, XX, 191-210.

IsER, Wolfgang (1971): The Act of Reading. A Theory of Aesthetic Response, Baltimore: Johns Hopkins University Press.

LiNKE, Angelika, Markus Nussbaumer y Paul Portmann (1991): Studienbuch Linguistik, Turingia: Niemeyer.

Mariottini, Laura (2006): «El uso de los diminutivos y su relación con la cortesía lingüística en los chats. Análisis contrastivo de comunidades virtuales españolas e italianas», Cultura, lenguaje y representación: revista de estudios culturales de la Universitat Jaume I, 3, 103-132.

Márquez Reiter, Rosina y María Elena Placencia (2005): Spanish Pragmatics, Houndmillas: Palgrave Macmillan.

Martín Zorraquino, María Antonia (2012): «Los diminutivos en español: aspectos morfológicos, semánticos y pragmáticos. Los valores estilísticos de los diminutivos y la teoría de la cortesía verbal», $<$ https://pdfs.semanticscholar.org/2a7c/7a2d7ff7c01ed501280d0155e4a8b903cedd.pdf>.

Mendoza, Martha (2005): «Polite diminutives in spanish. A matter of size? », en Robin Lakoff y Sachiko Ide, Broadening the Horizon of Linguistic Politeness, Ámsterdam/Filadelfia: John Benjamins, 163-173.

Monjour, Alf (2006): «"Pasad, pasad” - “Kommen Sie bitte rein”. Pedro Almodóvar, los actos de habla y la comparación intercultural», en Martina Schra-
der-Kniffki (ed.), La cortesía en el mundo hispano, 221 Madrid: Iberoamericana, 15-42.

Montero Curiel, Pilar (2008): «El proceso de lexicalización del diminutivo "ardilla"», Anuario de estudios filológicos, 31, 117-131.

Moser, Karolin (2006): «Variación entre formas ustedeantes y voseantes a nivel del discurso familiar en la clase media y alta en San José-Costa Rica», en Martina Schrader-Kniffki (ed.), La cortesía en el mundo hispano, Madrid: Iberoamericana, 97-116.

Newmark, Peter (1991): About Translation, Clevedon: Multilingual Matters.

Nord, Christiane (1991): Text Analysis in Translation. Theory, Method, and Didactic Application of a Model for Translation-Oriented Text Analysis. Translated from the German by Christiane Nord and Penelope Sparrow. Ámsterdam/Atlanta: Rodopi.

NíkLEVA, Dimitrinka (2011): «Consideraciones pragmáticas sobre la cortesía y su tratamiento en la enseñanza del español como L1», Tejuelo, 11, 64-84.

OhmanN, Richard (1971): «Speech Acts and the Definition of Literature», Philosophy \& Rhetoric, 4/1, 1-19.

Poveda Cabanes, Paloma (2008): «Uso y funciones comunicativas de los atenuantes retóricos en la memoria de arquitectura: un estudio inglés-español», Ibérica, 15, 113-134.

PyM, Anthony (1993): «Review of Christiane Nord (1991): Text Analysis in Translation. Theory, Method, and Didactic Application of a Model for Translation-Oriented Text Analysis, Amsterdam», TTR, 6/2, 184-190.

Ruiz de Mendoza, José (2000): «El modelo cognitivo idealizado de tamaño y la formación de aumentativos y diminutivos en español», Revista española de lingüística aplicada, 1 (extra), 355-374.

SEARLE, John Rogers (1975): «The Logical Status of Fictional Discourse», New Literary History, 6/2, 319-332.

SEARLE, John Rogers (1969): Speech acts. An Essay in the Philosophy of Language, Cambridge: Cambridge University Press.

STOLL, Eva (2006): «La fórmula de tratamiento señorita en el español peninsular comparada con el Fräulein en alemán. Modificaciones de significado y empleo», en Martina Schrader-Kniffki (ed.), La cortesía en el mundo hispano, Madrid: Iberoamericana, 79-96. 
222 TAYLOR, John (1989): Linguistic Categorization. Prototypes in Linguistic Theory, Oxford: Clarendon Press. Venuti, Lawrence (2012): The Translator's Invisibility. A History of Translation, Londres: Routledge.

VINAY, Jean-Paul y Jean DARBELnET (1958): Stylistique comparée du français et de l'anglais: méthode de traduction, París : Didier.

WaltereIT, Richard (2006): Zur Pragmatik und historischen Semantik von Modalpartikeln und ihren funktionalen Äquivalenten in romanischen Sprachen, Turingia: Niemeyer.

\section{Corpus}

MARSÉ, Juan (1966): Últimas tardes con Teresa. Edición digital alojada en <https://docs.google.com/viewer? $\mathrm{a}=\mathrm{v} \&$ pid=sites\&srcid=ZGVmYXVsdGRvbWFp bnxjYXNOZWxsYW5vZW5nZXNpfGd4OjQzMzE4 ZmI2YzAwZWJ1N2I>.

MARSÉ,Juan (1991): Letzte Tage mit Teresa, trad. Andrea Rössler, Múnich: Serie Piper. 